\title{
Opto-Structural Properties of Silicon Nitride Thin Films Deposited by ECR-PECVD
}

\author{
Hicham Charifi'1, Abdelilah Slaoui'2, Jean Paul Stoquert², Hassan Chaib ${ }^{3}$, \\ Abdelkrim Hannour ${ }^{1}$ \\ ${ }^{1}$ Laboratory of Condensed Matter Physics and Nanomaterials for Renewable Energy, University Ibn Zohr, \\ Agadir, Morocco \\ ${ }^{2}$ ICube, CNRS-Université de Strasbourg, Strasbourg, France \\ ${ }^{3}$ Research Group Materials and Energy, Polydisciplinary Faculty, Ibn Zohr University, Ouarzazate, Morocco \\ Email: hichamcharifi@gmail.com
}

Received 20 November 2015; accepted 27 December 2015; published 30 December 2015

Copyright (C) 2016 by authors and Scientific Research Publishing Inc.

This work is licensed under the Creative Commons Attribution International License (CC BY). http://creativecommons.org/licenses/by/4.0/

(c) (i) 0pen Access

\begin{abstract}
Amorphous hydrogenated silicon nitride thin films a-SiN $\mathrm{x}: \mathrm{H}$ (abbreviated later by $\mathrm{SiN}_{\mathrm{x}}$ ) were deposited by Electron Cyclotron Resonance plasma enhanced chemical vapor deposition method (ECR-PECVD). By changing ratio of gas flow $\left(\mathrm{R}=\mathrm{NH}_{3} / \mathrm{SiH}_{4}\right)$ in the reactor chamber different stoichiometric layers $x=[N] /[\mathrm{Si}]$ ([N] and [Si] atomic concentrations) are successfully deposited. Part of the obtained films has subsequently undergone rapid thermal annealing RTA $\left(800^{\circ} \mathrm{C} / 1 \mathrm{~s}\right)$ using halogen lamps. Optical and structural characterizations are then achieved by spectroscopic ellipsometry (SE), ion beam analysis and infrared absorption techniques. The SE measurements show that the tuning character of their refractive index $n(\lambda)$ with stoichiometry $x$ and their non-absorption properties in the range of 250 - $850 \mathrm{~nm}$ expect for Si-rich $\mathrm{SiN}_{\mathrm{x}}$ films in the ultraviolet $\mathrm{UV}$ range. The stoichiometry $x$ and its depth profile are determined by Rutherford backscattering spectrometry (RBS) while the hydrogen profile (atomic concentration) is determined by Elastic Recoil Detection Analysis (ERDA). Vibrational characteristics of the $\mathrm{Si}-\mathrm{N}, \mathrm{Si}-\mathrm{H}$ and $\mathrm{N}-\mathrm{H}$ chemical bonds in the silicon nitride matrix are investigated by infrared absorption. An atomic hydrogen fraction ranging from $12 \%$ to $22 \%$ uniformly distributed as evaluated by ERDA is depending inversely on the stoichiometry $x$ ranging from 0.34 to 1.46 as evaluated by RBS for the studied $\operatorname{SiN}_{x}$ films. The hydrogen loss after RTA process and its out-diffusion depend strongly on the chemical structure of the films and less on the initial hydrogen concentration. A large hydrogen loss was noted for non-thermally stable Si-rich $\mathrm{SiN}_{\mathrm{x}}$ films. Rich nitrogen films are less sensitive to rapid thermal process.
\end{abstract}

\section{Keywords}

ECR-PECVD, Silicon Nitride

How to cite this paper: Charifi, H., Slaoui, A., Stoquert, J.P., Chaib, H. and Hannour, A. (2016) Opto-Structural Properties of Silicon Nitride Thin Films Deposited by ECR-PECVD. World Journal of Condensed Matter Physics, 6, 7-16.

http://dx.doi.org/10.4236/wjcmp.2016.61002 


\section{Introduction}

Amorphous hydrogenated silicon nitride film $\left(\mathrm{SiN}_{\mathrm{x}}\right)$ deposited at low temperature by plasma assisted CVD has several applications in semiconductor and photovoltaic industry. $\mathrm{SiN}_{\mathrm{x}}$ films deposited by PECVD technique in all its variants exhibit several advantageous properties. It is a low temperature process, relatively cost-effective,

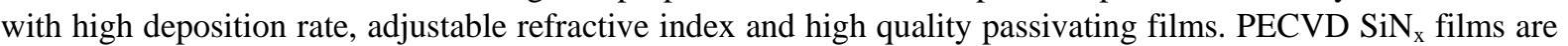
generally obtained by radio-frequency RF or/and a microwave (MW) electrical discharge in a nitrogen and silicon precursor gas mixture $\left(\mathrm{SiH}_{4}, \mathrm{NH}_{3}, \mathrm{~N}_{2} \mathrm{O}\right)$. Most PECVD techniques for deposition $\mathrm{SiN}_{\mathrm{x}}$ use pure or diluted silane $\left(\mathrm{SiH}_{4}\right)$ and ammonia $\mathrm{NH}_{3}$ at lower temperature $200^{\circ} \mathrm{C}-500^{\circ} \mathrm{C}$; alternative precursor gas could also be used. It is also possible to utilize both plasma generators in separate places. Collision of electrons with gas molecules causes a chain of ionization, dissociation and excitation reactions. Mainly two parameters that determine the plasma chemistry are the electron energy distribution function and the dissociation and ionization cross sections [1]. A detailed analysis of the plasma processes takes in consideration all the possible dissociation and ionization processes, and hence accurate study of plasma reaction is rather complex. Different physico-chemical

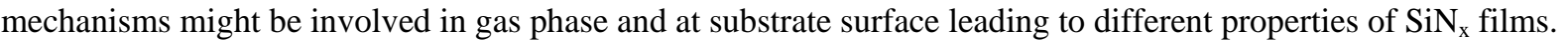
In $\mathrm{SiH}_{4} / \mathrm{N}_{2}$ plasma the radicals $\mathrm{SiH}_{\mathrm{m}}$ and $\mathrm{N}$ are the basic parameters responsible for depositing silicon nitride. Nevertheless, no precursor of $\mathrm{Si}-\mathrm{N}$ is reported to be present within the plasma [2] [3]. Aminosilanes $\mathrm{Si}\left(\mathrm{NH}_{2}\right)_{4}$ and $\mathrm{Si}\left(\mathrm{NH}_{2}\right)_{3}$ are shown to be dominant radicals in the gas phase thus responsible for depositing physico-chemical films in $\mathrm{SiH}_{4} / \mathrm{NH}_{3}$ plasma [4]. On substrate surface, deposition occurs by chemisorptions of silane and ammonia radicals. This process depends on substrate temperature, a deterministic property of a film.

$\mathrm{SiN}_{\mathrm{x}}$ films, compared to other dielectric films such as silicon dioxide, are more suitable candidates for photovoltaic applications. They are used as antireflecting coating (ARC), back surface reflector for optical purpose in the front and the back side of Si-based solar cells due to its tunable refractive index. By adjusting thickness and refractive index, stacking layers could also be used instead of a simple one to optimize the properties of solar cells efficiency. From electrical viewpoint, they are also used as hydrogen source for the bulk passivation of recombining centers in low-cost defected-rich Si-based solar cells thanks to the thermal post-deposition of metal contacts (mc-Si, poly-Si and ruban-Si) [5]-[7]. They can be used as surface passivating films for crystalline silicon based solar cells. As well since reducing silicon wafers thickness $(<100 \mu \mathrm{m})$ requires high quality surface passivating approach, particularly in the rear side to avoid solar cell bowing due to Al-pastes and to manufacture a high-efficiency solar cell [8]. Reducing surface recombination rate could be achieved by reducing interface states density $\mathrm{D}_{\text {it }}$ by depositing appropriate solid thin films or/and by reducing free carriers density at the interface by the fixed charges in the dielectric (field effect passivation) [9] [10], as reported in this reference [11].

In this work, we study the effect of the main technological parameters (i.e. the gas flow ratio), with keeping the other parameters constants, on the optical and structural properties of the $\mathrm{SiN}_{\mathrm{x}}: \mathrm{H}$ films produced in a remote Electron Cyclotron Resonance (ECR-) CVD reactor. The thermal stability of the deposited films will be probed after a rapid thermal anneal using halogen lamps as heating source.

\section{Experimental Details}

\subsection{Films Preparation}

Our $\mathrm{SiN}_{\mathrm{x}}$ films were deposited by a remote plasma ECR-PECVD system (Roth \& Rau). The system is made of a steel cylindrical chamber $(200 \mathrm{~mm} \times 350 \mathrm{~mm})$ containing a graphite support to ensure uniform heating of samples of $6 "$ diameter at a temperature range $100^{\circ} \mathrm{C}-500^{\circ} \mathrm{C}$, a lock for loading and unloading samples away from the reactor chamber, a pumping system for vacuum $\left(10^{-7} \mathrm{mbar}\right)$, a micro-wave plasma generator ECR (Electron Cyclotron Resonance at $2.45 \mathrm{GHz}$ ), a radio-frequency RF plasma generator at $13.56 \mathrm{MHz}$ and a six gas lines (Ar, $\mathrm{H}_{2}, \mathrm{~N}_{2}, \mathrm{NH}_{3}, \mathrm{SiH}_{4}, \mathrm{~N}_{2} \mathrm{O}$ ). Prior to the deposition, silicon substrates were cleaned in an oxidizing bath $\mathrm{H}_{2} \mathrm{SO}_{4} / \mathrm{H}_{2} \mathrm{O}_{2}$ (4/1) for 10 minutes, followed by rinsing with deionized water, then soaked in a hydrofluoric HF (10\%) acid solution for 30 seconds to remove the oxide, followed by a second rinsing with deionized water and drying with gas of nitrogen. The $1^{\text {st }}$ series $\mathrm{SiN}_{\mathrm{x}}$ films was deposited at $400^{\circ} \mathrm{C}$ under gas flow $\left(\left[\mathrm{SiH}_{4}\right]+\left[\mathrm{NH}_{3}\right]\right) \mathrm{of}^{\circ}$ 35 sccm. The partial flow of ammonia and silane are $(R=21 / 14,19 / 16,18 / 17$ and 17/18), respectively. AC electrical discharge parameters were unchanged and fixed at $500 \mathrm{~W}$ for the $\mathrm{Mw}$ power and $200 \mathrm{~W}$ for RF power. Latter series was also prepared to enlarge the $\mathrm{R}$ ratio while maintaining silane flow at $16 \mathrm{sccm}$. Ammonia flow was 5, 8, 19, 32 and $80 \mathrm{sccm}$. Ammonia is dissociated in the upper MW reactor chamber by absorbing micro- 
wave power. Silane is dissociated in the bottom of the reactor in the vicinity of the Si substrate by absorbing radiofrequency power.

$\mathrm{SiN}_{\mathrm{x}}$ films were deposited on one of the surfaces of the commercial Cz-Si substrates. Part of our films was rapid thermally annealed under halogen lamps in a FAV-4 oven from JIPELEC Company, simulating the firing metal contacts through the $\operatorname{SiN}_{\mathrm{x}}$ films.

\subsection{Films Characterization}

The optical properties of the obtained films were characterized by Perkin-Elmer UV/VIS/NIR Spectrometer Lambda 19 using a slit of $2 \mathrm{~nm}$ for the reflectivity measurements. A "Gaertner" single-wavelength (632.8 nm) ellipsometer equipped with He-Ne laser was used to determine the refractive index and the deposition rate of $\mathrm{SiN}_{\mathrm{x}}: \mathrm{H}$ films. Spectroscopic ellipsometry measurements in the range $250-850 \mathrm{~nm}$ were performed using JobinYvon UVISEL ellipsometer. The chemical structure of $\mathrm{SiN}_{\mathrm{x}}$ films were analyzed by fourier-transform infrared spectroscopy (FTIR), Infrared-transmission measurements were performed on a Bruker Equinox 55 Fourier transform infrared spectrometer using a MIR-source, a $\mathrm{KBr}$ beamsplitter and DTGS detector. FT-IR spectra were collected from 5000 to $400 \mathrm{~cm}^{-1}$ with resolution of $2 \mathrm{~cm}^{-1}$, using a spot diameter of $15 \mathrm{~mm}$ of exposed area circle of $1.77 \mathrm{~cm}^{2}$ and for each spectrum 256 scans were accumulated to improve the signal-to-noise ratio. The compositional properties (Si, N, H content) were determined by Rutherford Backscattering spectrometry (RBS) and Elastic Recoil Detection Analysis (ERDA) at the van de Graff accelerator of Strasbourg University.

RBS probe number and energy of backscattered ions after interaction with the target sample giving then the atomic masses and the elemental concentrations of the chemical elements ( $\mathrm{Si}$ and $\mathrm{N}$ ) in regard to the film depth. The ERD is used peculiarly to probe light elements such as hydrogen. The kinematic collision is similar to RBS. For ERDA, we are exceptionally interested in recoiled atoms. ERD measurements were carried out using an analyzing ion beam of $2.9 \mathrm{MeV}^{4} \mathrm{He}^{+}$particles at $75^{\circ}$ detection angle from the normal to the sample. A $2 \mathrm{MeV}$ ${ }^{4} \mathrm{He}^{+}$particles beam with a $150^{\circ}$ backscattering angle used for RBS. SAM code is used to treat the collected data (It performs iterative simulations assuming an initial composition and then finding a set of input parameters giving the best fit of the experimental spectrum with that calculated).

\section{Results \& Discussion}

\subsection{Optical Properties}

Figure 1 shows the variation of optical constants $n(\lambda)$ and $k(\lambda)$ of as-deposited $\operatorname{SiN}_{x}$ films of the first series with a ratio $\mathrm{R}$ ranging from $0.8(\mathrm{R}=17 / 18)$ to $1.5(\mathrm{R}=21 / 14)$. Tauc-Lorentz dispersion model was used to calculate the optical constants from the ellipsometric angles $\Delta$ and $\Psi$ [12]. SE data are fitted by minimizing the value of $\chi^{2}$ representing the difference between the calculated and the experimental data [13]. The refractive index increases when the gas ratio $\mathrm{R}$ decreases since Si-content (proved by RBS, see Table 1) in the films increases. They varies from 1.9 for a film with $(\mathrm{R}=1.5)$ to 2.4 for a film with $\mathrm{R}=0.8$ at a $633 \mathrm{~nm}$ wavelength.

Similar observations were made for the latter series, the refractive index $\mathrm{n}(633 \mathrm{~nm})$ varies between 1.95 for $\mathrm{R}$ $=5$ and 3.35 for $\mathrm{R}=0.3$. This evolution is abrupt for ratios $\mathrm{R}<2$. Indeed, when the silicon content increases due to high density of silane precursors $\mathrm{SiH}_{\mathrm{x}}$, the refractive index of the Si-rich films approaches to that of c-Si $(\mathrm{n}=$ 3.42). However, the refractive index of as-deposited $\operatorname{SiN}_{\mathrm{x}}$ films with a $\mathrm{R}>2$ is quasi-constant and close to that of stoichiometric silicon nitride $\mathrm{n}\left(\mathrm{Si}_{3} \mathrm{~N}_{4}\right)=1.97$. This inferior limit is most likely due to the saturation of $\mathrm{NH}_{\mathrm{x}}$

Table 1. Silicon, Nitrogen and hydrogen content for the ECR-PECVD $\mathrm{SiN}_{\mathrm{x}}$ with different gas flow ratio R determined by RBS and ERDA prior to and subsequent to RTA indicated by the dep and an subscripts, respectively. The corresponding refractive index and optical gap are determined by SE (column 6).

\begin{tabular}{ccccccc}
\hline $\mathrm{R}=\mathrm{NH}_{3} / \mathrm{SiH}_{4}$ & $\mathrm{Si}_{\text {dep }} / \mathrm{Si}_{\text {an }}$ & $\mathrm{N}_{\text {dep }} / \mathrm{N}_{\mathrm{an}}$ & $\mathrm{H}_{\text {dep }} / \mathrm{H}_{\mathrm{an}}$ & $\mathrm{x}_{\text {dep }} / \mathrm{x}_{\text {an }}$ & $\mathrm{n}(633 \mathrm{~nm}) / \mathrm{E}_{\mathrm{g}}(\mathrm{eV})$ & Total atomic N $\left(\mathrm{at} / \mathrm{cm}^{3}\right)$ \\
\hline $08 / 16$ & $0.58 / 0.73$ & $0.2 / 0.26$ & $0.22 / 0.01$ & $0.34 / 0.36$ & $2.79 / 1.7$ & $5.98 \times 10^{22}$ \\
$19 / 16$ & $0.41 / 0.51$ & $0.37 / 0.41$ & $0.22 / 0.07$ & $0.93 / 0.8$ & $2.32 / 2.38$ & $7.82 \times 10^{22}$ \\
$32 / 16$ & $0.40 / 0.54$ & $0.44 / 0.37$ & $0.15 / 0.09$ & $1.1 / 0.68$ & $2.01 / 2.75$ & $9.42 \times 10^{22}$ \\
$80 / 16$ & $0.34 / 0.4$ & $0.46 / 0.48$ & $0.15 / 0.12$ & $1.35 / 1.2$ & $1.95 / 3.8$ & $1.31 \times 10^{23}$ \\
\hline
\end{tabular}




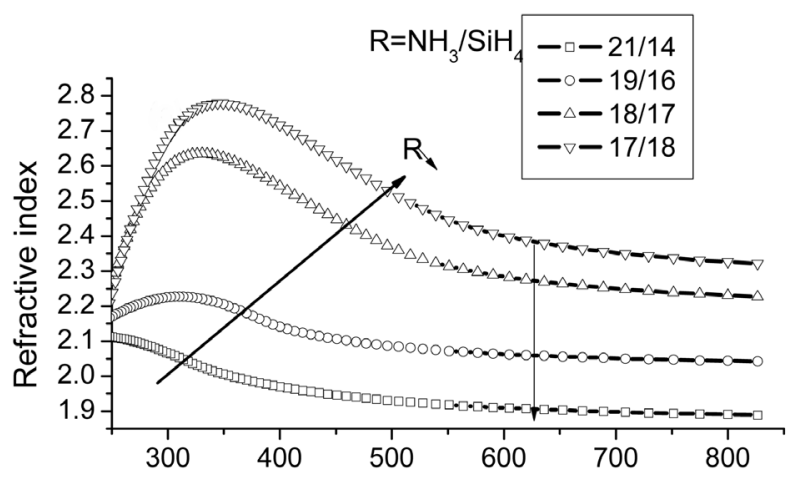

(a)

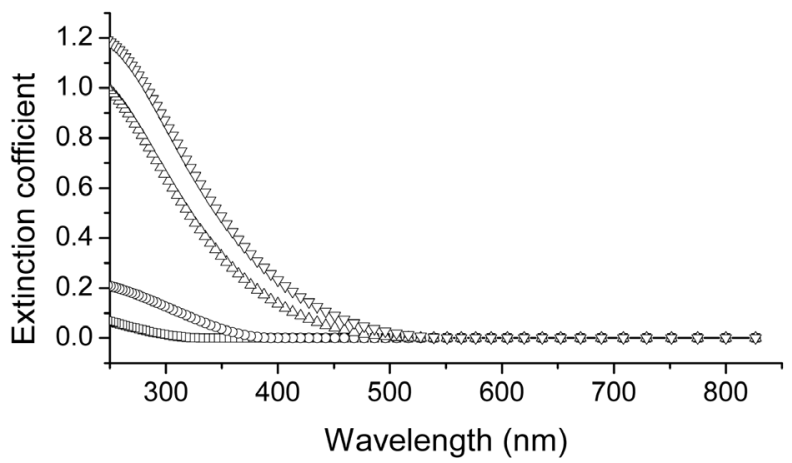

(b)

Figure 1. Wavelength-dependant (a) refractive index $\mathrm{n}(\lambda)$ and (b) extinction coefficient $\mathrm{k}(\lambda)$ of a-SiN $\mathrm{x}$ :H films obtained by ECR-PECVD as function of gas flow ratio $\mathrm{R}$.

radicals resulting from $\mathrm{NH}_{3}$ dissociation. We can note a similar trend in literature [14]. These results allow adjusting the refractive index of $\mathrm{SiN}_{\mathrm{x}}$ films by simply setting $\mathrm{NH}_{3}$ and $\mathrm{SiH}_{4}$ gas flow. The corresponding extinction coefficient $\mathrm{k}$ (from which the absorption coefficient can be calculated $(\alpha=4 \pi \mathrm{k} / \lambda)$ ) is quasy null for the high ratio $\mathrm{R}$ of the as-deposited films. The films are then transparent in the region 250 - $850 \mathrm{~nm}$ and more suitable for ARCs. However, the extinction coefficient amplitude significantly increases to become wider nearby lower wavelengths (ultraviolet), due to a progressive replacement of Si-N bonds by highly absorbent Si-Si bonds [15]. An optical study at a single wavelength $632.8 \mathrm{~nm}$ shows the same dependence of the refractive index on the gas ratio $\mathrm{R}$, as well. The deposition rate decreases from $22.75 \mathrm{~nm} / \mathrm{min}$ to $17 \mathrm{~nm} / \mathrm{min}$ when the ratio $\mathrm{R}$ increases for the first series. This could be explained by chemical recombination of the reactive species outside of the deposition surface for plasma with a high ratio R. The kinematic of the deposition with a low $\mathrm{R}$ is controlled by silane precursors $\mathrm{SiH}_{\mathrm{x}}$. The deposition rate increases for higher silicon in the gaseous phase. The refractive index depends slightly on the deposition period confirming that the $\mathrm{SiN}_{\mathrm{x}}$ films are fairly more uniform towards depth (proved by RBS, see Figure 4(b)).

Assuming parabolic bands, the optical gap could be determined either by modeling SE data via a dispersion model or by using the Tauc relationship

$$
(\alpha \mathrm{E})^{1 / 2}=\mathrm{B}\left(\mathrm{E}-\mathrm{E}_{\mathrm{g}}\right)
$$

where $E_{g}, B$ are the optical gap and the Tauc constant, respectively. Values of $E_{\mathrm{g}}$ reported by different authors are generally limited by those simulated by SSM (Stoechiometric Statistical Model) and RBM (Random Bonding Model) [16] [17]. The optical gap of our $\mathrm{SiN}_{\mathrm{x}}$ films varies globally from $1.7 \mathrm{eV}$ to $3.8 \mathrm{eV}$ according to the refractive index of the films for the two series, comparables to that in the literature [18]. The optical gap $\mathrm{E}_{\mathrm{g}}$ has a minimum $1.7 \mathrm{eV}$ for Si-rich $\mathrm{SiN}_{\mathrm{x}}$ films $\mathrm{R}=0.5$, mainly determined by the $\mathrm{Si}-\mathrm{H}$ and $\mathrm{Si}-\mathrm{Si}$ bonds. It increases quite rapidly to a limit value of $3.8 \mathrm{eV}$ as the refractive index $\mathrm{n}$ decreases to value close that of $\mathrm{Si}_{3} \mathrm{~N}_{4}$ ( $\left(\mathrm{see} \mathrm{Fig-}^{-}\right.$ ure 2, Table 1). This is mainly due to the optical properties controlled by Si-N and N-H bonds [19]. 


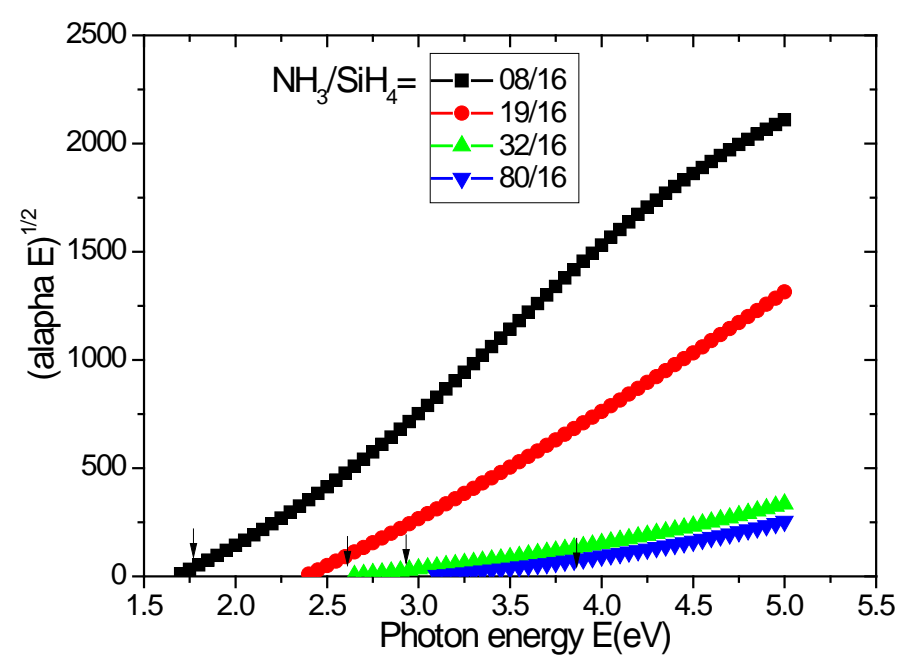

Figure 2. Tauc's plots for ECR-PECVD a-SiN ${ }_{\mathrm{x}}: \mathrm{H}$ according to different gas flow ratios $\mathrm{R}$.

Tauc slope B could provide details on the spreading tails of valence and conduction bands. Figure 3 shows the dependence of $\mathrm{B}$ on the refractive index (inversely proportional to stoichiometry $\mathrm{x}$ ). It gradually decreases with the stoichiometry $\mathrm{x}$, it has a value of $700 \mathrm{~cm}^{-1 / 2} \mathrm{eV}^{1 / 2}$ for a film with $(\mathrm{n}=2.79, \mathrm{x}=0.34)$ and then stabilizes at a minimum value of $130 \mathrm{~cm}^{-1 / 2} \mathrm{eV}^{1 / 2}$ for a film with $(\mathrm{n}=1.95, \mathrm{x}=1.34)$. The $\mathrm{B}$ shift reasoning is similar to that of optical band gap. For lower values of $\mathrm{x}$, the superficial centers $\equiv \mathrm{Si}-\mathrm{Si} \equiv$ and $=\mathrm{N}$ form queues at the valence band. As far as the stoichiometry increases, much of the Si-Si bonds are broken resulting in dangling bonds $\equiv$ Si that expand the band tails and gives rise to a very important local disorder. With stoichiometries $\mathrm{x}>1$, the expansion of band tails is reduced and therefore the Tauc slope B stabilizes. This finding is consistent with what has been reported in this reference [20].

Experimental observations subsequent to a RTA depend on the annealing cycle (temperature and annealing time) and the structure of the film. Thus, $\mathrm{SiN}_{\mathrm{x}}$ films can be categorized into two types: the quasi-stoichiometric films with a low refractive index whose optical properties are almost unchangeable and thickness decreased slightly with 2 - $5 \mathrm{~nm}$ after RTA step. The latter category is that of the Si-rich films with an initial refractive index $n>2.1$ whose refractive index and extinction coefficient significantly increases after RTA. The optical gap $E_{g}$ of the N-rich films increases slightly unlike the Si-rich films; it decreases and approaches that of amorphous silicon a-Si. These experimental findings, confirmed by reflectivity measurements, are consistent with the results of some authors [21] [22]. This is can be correlated to the change of the structural properties as result of local rearrangement of the $\mathrm{Si}-\mathrm{H}, \mathrm{N}-\mathrm{H}$ bonds following a densification of the N-rich $\mathrm{SiN}_{\mathrm{x}}$ films and a high outdiffusion rate of hydrogen for the Si-rich films.

\subsection{Structural Properties: RBS, ERDA, Infrared Measurements}

Bustarret et al. [23] have proposed a method to infer the stoichiometry of a- $\operatorname{SiN}_{\mathrm{x}}$ films from their refractive indices. In our case, the $x$ values are quite different from that determined by RBS. This mismatch is likely due to hydrogen and possible voids in the SiN matrix. The stoichiometry may be also indirectly determined from infrared spectroscopy using the ratio $[\mathrm{Si}-\mathrm{H}] /[\mathrm{N}-\mathrm{H}]$ by this equation

$$
\frac{\mathrm{Si}}{\mathrm{N}}=0.084+\frac{\mathrm{Si}-\mathrm{H}}{\mathrm{N}-\mathrm{H}} \times 0.70
$$

RBS analysis does not show other elements (oxygen, carbon) in the bulk of the as-deposited SiN films or its atomic content less than the detection threshold, except in rare cases where residual oxygen can exist on the surface due to inadvertent oxidation. Besides, it also confirms that silicon and nitrogen are uniformly distributed over the bulk of the films except on small atomic layers on the surface and at the interface with the silicon substrate. The channels number (x axis in RBS spectra) is related to the energy loss that can be converted into thickness. The first plate in the RBS spectrum at high channel numbers is relative to the $\mathrm{Si}$ in the $\mathrm{SiN}_{\mathrm{x}}: \mathrm{H}$ film 


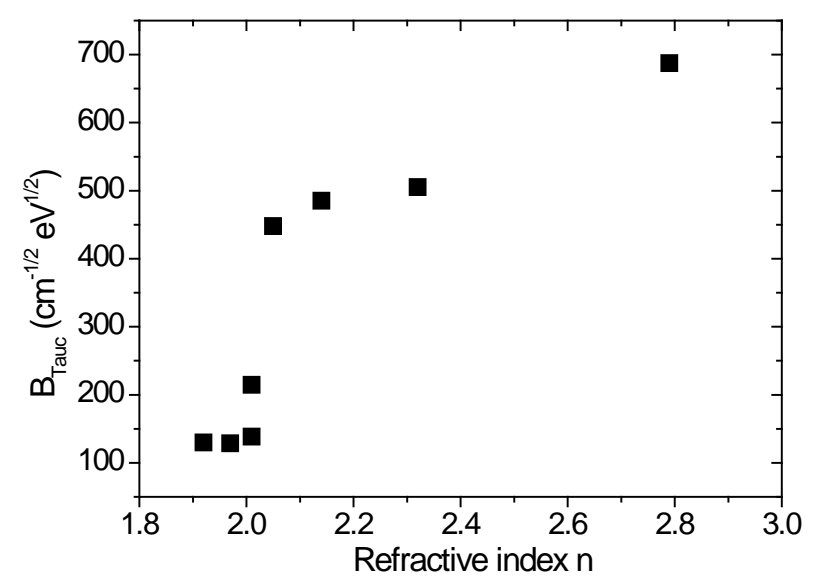

Figure 3. Tauc slope as function of refractive index for the asdeposited ECR-PECVD a-SiN $:$ H films.

while the second plate relative to the $\mathrm{N}$ is flooded in that of Si substrate. The latter is not flat due to the channelling effect when the particles pass through the crystal structure of the substrate. The areal densities of each chemical element ( $\mathrm{Si}$ and $\mathrm{N}$ ) constituting the film, representing the product atomic volume density $\times$ thickness $\left(\mathrm{n} \times \mathrm{e}\right.$ atoms $\left./ \mathrm{cm}^{2}\right)$, may be derived from its corresponding peak area (see Figure 4(b)). A fairly linear relationship is noticed between the refractive index and the inverse of stoichiometry with a slope of 0.57 close to that reported by S. Dauwe [24]. It is then possible to estimate the stoichiometry of the films by simple measurement of refractive index. Concerning the hydrogen (by ERDA), it is almost uniformly distributed over the thickness of the film, but the non-symmetrical shape of its profile, especially towards the interface shows that it can possibly diffuse into the bulk of the substrate during deposition and/or the $\mathrm{Si} / \mathrm{SiN}$ interface is very rough. It appears that hydrogen is deeper diffused in the case of plasma rich in nitrogen precursors (see Figure 4(a)). Table 1 summarizes the analysis results by RBS, ERDA and spectroscopic ellipsometry of the two series of $\mathrm{SiN}_{\mathrm{x}}$ films as function of the gas flow ratio R. The stoichiometry $\mathrm{x}\left(2^{\text {nd }}\right.$ series by RBS) increases monotonically from 0.34 to 1.34 as the $\mathrm{R}$ ratio goes up from 0.5 to 5 . The film with low $\mathrm{R}=0.5(\mathrm{x}=0.34)$ is rich in silicon. This could explain the higher refractive index of $n=2.79$. When the ratio $R$ increases, the film becomes richer in nitrogen and its structure approaches to that of the stoichiometric silicon nitride for a ratio $\mathrm{R}>2(\mathrm{x}=1.34)$. This finding is consistent with that by SE.

Stoichiometry of our films is primarily determined by the ratio R. Furthermore, Hydrogen content (determined by ERDA) drops as the stoichiometry of the film increases. These findings in conjunction with those by IR absorption show that the hydrogen is mainly related to the $\mathrm{Si}$ with a content of $22 \%$ for the films with $(\mathrm{R}=$ $0.5, \mathrm{x}=0.34)$ and its content down to $15 \%$ for the films with $(\mathrm{R}=5, \mathrm{x}=1.34)$ wherein the hydrogen is mostly bonded to the nitrogen. Michael et al. [25] reported an increase in the hydrogen content with an increasing $\mathrm{x}$ of $\mathrm{SiN}_{\mathrm{x}}$ films deposited using a mixture of $\mathrm{SiH}_{4} / \mathrm{N}_{2} / \mathrm{H}_{2}$ gas. Lauinger et al. [26] reported that [H] remains at about $\sim 10^{22} \mathrm{~cm}^{-3}$ and does not follow any particular change with the stoichiometry of the film. In general, the difference in hydrogen content is attributed to the differences in bonds densities [Si-H] and $[\mathrm{N}-\mathrm{H}]$. The reaction mechanisms and the deposition techniques are deterministic in this regard. Literature Hydrogen content of $20 \%$ $30 \%$ is generally used for plasma reactors [27] [28].

FTIR spectra with strong peak at $845 \mathrm{~cm}^{-1}$ and two peaks at $2150 \mathrm{~cm}^{-1}$ and $3330 \mathrm{~cm}^{-1}$ of different intensity and shape as a function of the ratio R, correspond to stretching modes of Si-N, Si-H and N-H bonds, respectively. Hydrogen content in the $\mathrm{SiN}_{\mathrm{x}}$ films could also be estimated from FTIR measurements by the semi-empirical method developed by Lanford and Rand [29]. Despite the enormous use of FTIR in the analysis of chemical bonds in the hydrogenated thin film a-Si:H, a-SiN:H and a-C:H. Several values of conversion factors for the various bonds (oscillators) have been reported in the literature [30] [31]. Verlann et al. [32] have first recalibrated these conversion factors in the case of $\operatorname{SiN}_{x}$ films by ERDA technique according to its stoichiometry. Figure 5 shows the dependence of the Si-N, Si-H and N-H absorption bands on the gas flow ratio R. The (700 $1100 \mathrm{~cm}^{-1}$ ) characteristic absorption band of Si-N largely depends on the ratio R. Its maximum position (830 $\mathrm{cm}^{-1}$ ) shows that SiN films are less contaminated by others elements during deposition and characterization. 


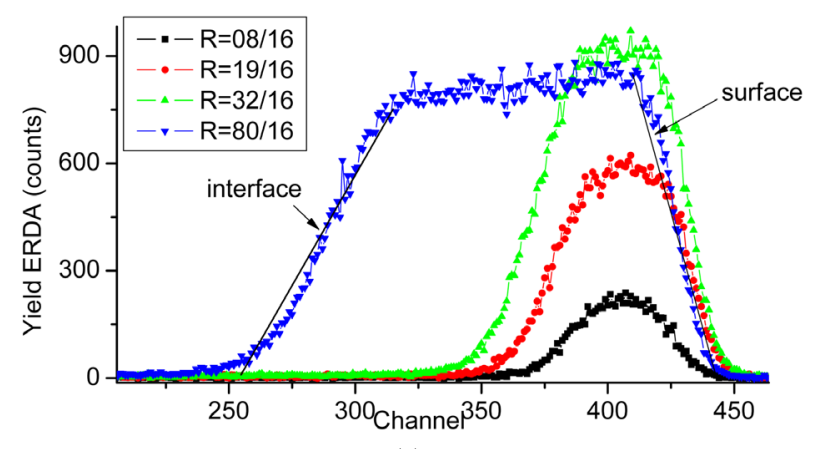

(a)

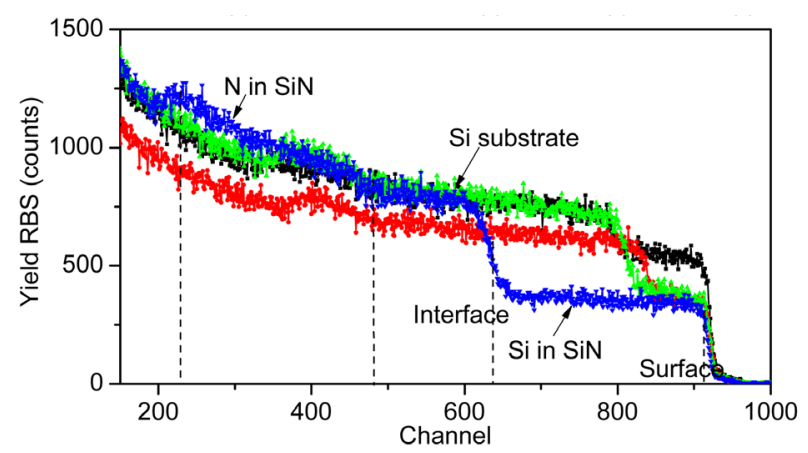

(b)

Figure 4. ERDA (a) and RBS (b) spectra for ECR-PECVD $\mathrm{SiN}_{\mathrm{x}}$ films as function of gas flow ratio $\mathrm{R}$.

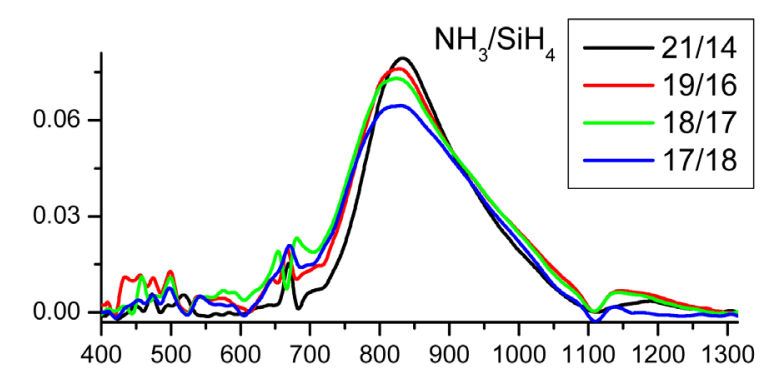

(a)

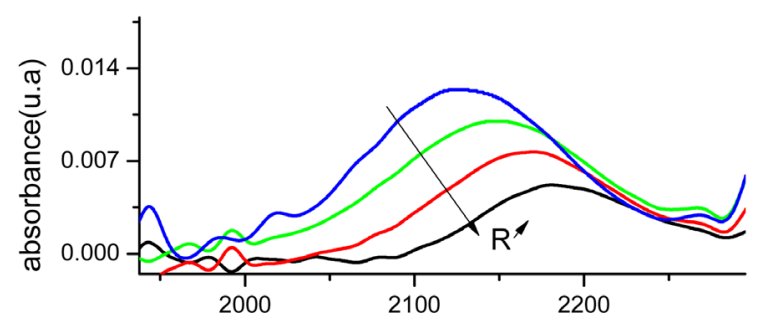

(b)

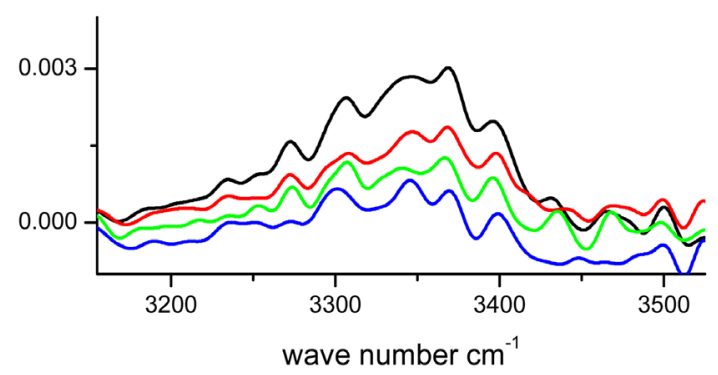

(c)

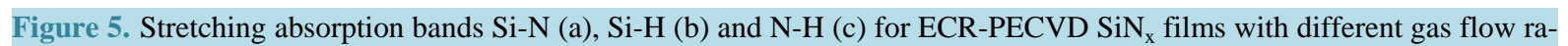
tios.

Particularly, oxygen atoms induce an increase of the maximum position due to electronegativity difference between $\mathrm{O}(3.5)$ and $\mathrm{N}(3.1)$. Hence, the oscillator strength of Si-N increases when oxygen is back bound to $\mathrm{N}$ atoms [33]. Its full width at half maximum FWHM provides information on the local order, it decreases when increasing the gas flow ratio $\mathrm{R}$. This shows that the structure of the film approaches that of stoichiometric $\mathrm{Si}_{3} \mathrm{~N}_{4}$, 
the Si and N atoms are bonded with each other and lowering the hydrogen content. Area under the Si-H peak, representing $\mathrm{Si}-\mathrm{H}$ bond surface concentration, increases when the gas flow ratio $\mathrm{R}$ decreases unlike those associated with the Si-N and N-H peaks. The Si-H peak maximum position increases from $2124 \mathrm{~cm}^{-1}$ to $2180 \mathrm{~cm}^{-1}$ with increasing the gas flow ratio $\mathrm{R}$. This shows that the number of bonded nitrogen atoms back to the $\mathrm{H} \equiv \mathrm{Si}$ increases. Hence, it reduces the interatomic distance and consequently increases its effective force constant [34].

Subsequent to RTA process, Stoichiometry of our $\mathrm{SiN}_{\mathrm{x}}$ films with a ratio of $(\mathrm{R}>1.19)$ decreases due to $\mathrm{Si}$ enrichment confirmed by an increase of their refractive index (see Table 1). The Si-H peak maximum is more shifted to low wavenumbers with less amplitude for films with $\mathrm{R}>1.19(19 / 16)$ indicating that much the films contain nitrogen, much are thermally stable. This confirms the results of the RTA effect on the optical properties. ERDA results show that hydrogen loss decreases gradually as the stoichiometry $\mathrm{x}$ increases (see Table 1 ). This is in agreement with FTIR results: hydrogen diffuses-out mainly by breaking $\mathrm{Si}-\mathrm{H}$ bonds $(3.1 \mathrm{eV})$ for Si-rich $\mathrm{SiN}_{\mathrm{x}}$ films with a low stoichiometry $\mathrm{x}$ and less by breaking $\mathrm{N}-\mathrm{H}$ bonds $(4.1 \mathrm{eV})$ for $\mathrm{N}$-rich $\mathrm{SiN}_{\mathrm{x}}$ films. The released hydrogen is of importance for deactivating the electrically active defects in solar-grade silicon substrates [35] [36]. The bulk passivation efficiency is not necessarily determined by the amount of desorbed hydrogen during annealing. A small fraction $(0.1 \%-1 \%)$ with respect to that initially contained $\sim 10^{22} \mathrm{~cm}^{-3}$ is sufficient to deactivate the recombination centers (grain boundaries, dislocations and impurities) [21] [37]. The structure of the $\mathrm{SiN}_{\mathrm{x}}$ films whatever the deposition method is a fundamental parameter that determines the dissociation mechanism of the hydrogen-containing molecules and its future diffusion mechanism in the silicon [38].

\section{Conclusion}

Hydrogenated silicon nitride films were successively deposited at $400^{\circ} \mathrm{C}$ by ECR-PECVD. The effect of the gas flow ratio $\mathrm{R}=\mathrm{NH}_{3} / \mathrm{SiH}_{4}$ was investigated for two series of samples. The former was by varying both the ammonia and the silane flow; the latter was by maintaining constant silane flow and varying ammonia flow. We noticed that the ratio has significant effect on the structural and optical properties. Composition and the bonding configurations of our material were determined by RBS, and infrared absorption, respectively. Optical properties were (refractive index, absorption coefficient and the optical gap) linked to the chemical composition of silicon nitride $\mathrm{x}=[\mathrm{N}] /[\mathrm{Si}]$. The content of hydrogen $11 \%$ and $22 \%$ depended also on film stoichiometry. ERDA and FTIR measurements suggest that the films composition is decisive in desorption mechanism of hydrogen.

\section{References}

[1] Kim, Y.K. and Rudd, M.E. (1994) Binary-Encounter Dipole Model for Electron Impact Ionization. Physical Review A, 50, 3954-3967. http://dx.doi.org/10.1103/PhysRevA.50.3954

[2] Smith, D.L. (1993) Controlling the Plasma Chemistry of Silicon Nitride and Oxide Deposition from Silane. Journal of Vacuum Science \& Technology A, 11, 1843. http://dx.doi.org/10.1116/1.578436

[3] Smith, D.L., Alimonda, A.S. and von Preissig, F.J. (1990) Mechanism of $\mathrm{SiN}_{\mathrm{x}} \mathrm{H}_{\mathrm{y}}$ deposition from $\mathrm{N}_{2}-\mathrm{SiH}_{4} \mathrm{Plasma}$ Journal of Vacuum Science \& Technology B, 8, 551. http://dx.doi.org/10.1116/1.585008

[4] Smith, D.L., Alimonda, A.S., Chau-Chen, C., Ready, S.E. and Wacker, B. (1990) Mechanism of $\mathrm{SiN}_{\mathrm{x}} \mathrm{H}_{\mathrm{y}} \mathrm{Deposition}$ from $\mathrm{NH}_{3}-\mathrm{SiH}_{4}$ Plasma. Journal of the Electrochemical Society, 137, 614-623. http://dx.doi.org/10.1149/1.2086517

[5] Hezel, R. and Schorner, R. (1981) Plasma Si Nitride—A Promising Dielectric to Achieve High-Quality Silicon MIS/IL Solar Cells. Journal of Applied Physics, 52, 3076. http://dx.doi.org/10.1063/1.329058

[6] Leguijt, C., et al. (1996) Low Temperature Surface Passivation for Silicon Solar Cells. Solar Energy Materials and Solar Cells, 40, 297-345. http://dx.doi.org/10.1016/0927-0248(95)00155-7

[7] Aberle, A.G. and Hezel, R. (1997) Progress in Low-Temperature Surface Passivation of Silicon Solar Cells Using Remote-Plasma Silicon Nitride. Progress in Photovoltaics, 5, 29. http://dx.doi.org/10.1002/(SICI)1099-159X(199701/02)5:1<29::AID-PIP149>3.0.CO;2-M

[8] Hofmann, M., Schneiderlöchner, E., Wolke, W. and Preu, R. (2004) Silicon Nitride-Silicon Oxide Stacks for Solar Cell Rear Side Passivation. 19th European Photovoltaic Solar Energy Conference Proceeding, Paris, 7-11 June 2004, 10371040 .

[9] Duerinckx, F. and Szlufcik, J. (2002) Defect Passivation of Industrial Multicrystalline Solar Cells Based on PECVD Silicon Nitride. Solar Energy Materials and Solar Cells, 72, 231-246. http://dx.doi.org/10.1016/S0927-0248(01)00170-2

[10] Wolf, S., Agostinelli, G. and Beaucarne, G. (2005) Influence of Stoichiometry of Direct Plasma-Enhanced Chemical 
Vapor Deposited [SiNx] Films and Silicon Substrate Surface Roughness on Surface Passivation. Journal of Applied Physics, 97, Article ID: 063303. http://dx.doi.org/10.1063/1.1861138

[11] Aberle, G. (2000) Progress in Photovoltaic. Research and Applications, 8, 473-487. http://dx.doi.org/10.1002/1099-159X(200009/10)8:5<473::AID-PIP337>3.3.CO;2-4

[12] Jellison Jr., G.E. and Modine, F.A. (1996) Parameterization of the Optical Functions of Amorphous Materials in the Interband Region. Applied Physics Letters, 69, 371-373, 2137.

[13] Tompkins, H.G. and Irene, E.A. (2005) Chapter 2-3: Handbook of Ellipsometry. William Andrew Publishing, Springer-Verlag, Norwich. http://dx.doi.org/10.1007/3-540-27488-X

[14] Soppe, W., Rieffe, H. and Weeber, A. (2005) Bulk and Surface Passivation of Silicon Solar Cells Accomplished by Silicon Nitride Deposited on Industrial Scale by Microwave PECVD. Progress in Photovoltaics: Research and Applications, 13, 551-569. http://dx.doi.org/10.1002/pip.611

[15] Yin, Z. and Smith, F.W. (1990) Optical Dielectric Function and Infrared Absorption of Hydrogenated Amorphous Silicon Nitride Films: Experimental Results and Effective-Medium-Approximation Analysis. Physical Review B, 42, 3666-3675. http://dx.doi.org/10.1103/PhysRevB.42.3666

[16] Ingo, G.M., Zacchetti, N., Della Sala, D. and Coluzza, C. (1989) X-Ray Photoelectrons Spectroscopy Investigation on the Chemical Structure of Amorphous Silicon Nitride (a-SiNx). Journal of Vacuum Science and Technology, 7, 30483055. http://dx.doi.org/10.1116/1.576314

[17] Philipp, H.R. (1973) Optical Properties of Silicon Nitride. Journal of the Electrochemical Society, 120, 295-300. http://dx.doi.org/10.1149/1.2403440

[18] Robertson, J. and Powell, M.J. (1983) Gap States in Silicon Nitride. Applied Physics Letters, 44, 415-417.

[19] Dupont, G., Caquineau, H., Despax, B., Berjoan, R. and Dollet, A. (1997) Structural Properties of N-Rich a-Si-N:H Films with Low Electron-Trapping Rate. Journal of Physics D: Applied Physics, 30, 1064-1076. http://dx.doi.org/10.1088/0022-3727/30/7/002

[20] Robertson, J., Warren, W.L. and Kanicki, J. (1995) Nature of Si and N Dangling Bonds in Silicon Nitride. Journal of Non-Crystalline Solids, 187, 297-300. http://dx.doi.org/10.1016/0022-3093(95)00153-0

[21] Hong, J., Kessels, W.M.M., Soppe, W.J., Rieffe, H.C., Weeber, A.W. and Van Desanden, M.C.M. (2003) Structural Film Characteristics Related to the Passivation Properties of High-Rate $(>0.5 \mathrm{~nm} / \mathrm{s})$ Plasma Deposited a-SiN ${ }_{\chi}: H$. Proceedings of 3rd World Conference on Photovoltaic Energy Conversion, Osaka, 11-18 May 2003, 1158-1161. http://dx.doi.org/10.1109/WCPEC.2003.1306121

[22] Cai, L., Rohatgi, A., Ang, D. and El-Sayed, M.A. (1996) Effects of Rapid Thermal Anneal on Refractive Index and Hydrogen Content of Plasma-Enhanced Chemical Vapor Deposited Silicon Nitride Films. Journal of Applied Physics, 80, 5384-5388. http://dx.doi.org/10.1063/1.363480

[23] Bustarret, E., Bensouda, M., Habrard, M.C. and Bruyère, J.C. (1988) Configurational Statistics in a-SixNyHz Alloys: A Quantitative Bonding Analysis. Physical Review B, 38, 8171-8184. http://dx.doi.org/10.1103/PhysRevB.38.8171

[24] Dauwe, S. (2003) Low Temperature Surface Passivation of Crystalline Silicon and Its Application to the Rear Side of Solar Cells. PhD Thesis, Hannover University, Hannover.

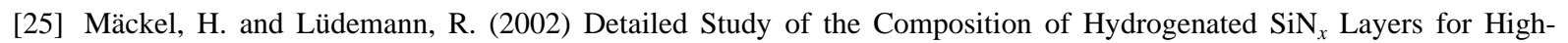
Quality Silicon Surface Passivation. Journal of Applied Physics, 92, 2602. http://dx.doi.org/10.1063/1.1495529

[26] Lauinger, T., Moschner, J., Aberle, A.G. and Hezel, R. (1998) Optimization and Characterization of Remote PlasmaEnhanced Chemical Vapor Deposition Silicon Nitride for the Passivation of P-Type Crystalline Silicon Surfaces. Journal of Vacuum Science \& Technology A, 16, 530. http://dx.doi.org/10.1116/1.581095

[27] Lauinger, T., Aberle, A.G. and Hezel, R. (1997) Comparison of Direct and Remote PECVD Silicon Nitride Films for Low-Temperature Surface Passivation of P-Type Crystalline Silicon. Proceedings of the 14th European Photovoltaic Solar Energy Conference, Barcelona, 30 June-4 July 1997, 853.

[28] Morello, G. (1995) Hydrogen Content of Amorphous PECVD SiN ${ }_{x}:$ H Films by Infrared Spectroscopy and Hydrogen Forward Scattering Results. Journal of Non-Crystalline Solids, 187, pp. 308-312. http://dx.doi.org/10.1016/0022-3093(95)00155-7

[29] Lanford, W.A. and Rand, M.J. (1978) The Hydrogen Content of Plasma-Deposited Silicon Nitride. Journal of Applied Physics, 49, 2473-2477. http://dx.doi.org/10.1063/1.325095

[30] Shih, A., Yeh, S.-H., Lee, S.-C. and Yang, T.R. (2001) Structural Differences between Deuterated and Hydrogenated Silicon Nitride/Oxynitride. Journal of Applied Physics, 89, 5355. http://dx.doi.org/10.1063/1.1364645

[31] Demichelis, F., Giorgis, F. and Perri, C.F. (1996) Compositional and Structural Analysis of Hydrogenated Amorphous Silicon-Nitrogen Alloys Prepared by Plasma-Enhanced Chemical Vapour Deposition. Philosophical Magazine Part B, 74, 155-168. http://dx.doi.org/10.1080/01418639608240333 
[32] Verlaan, V., van der Werf, C.H.M., Arnoldbik, W.M., Goldbach, H.D. and Schropp, R.E.I. (2006) Unambiguous Determination of Fourier-Transform Infrared Spectroscopy Proportionality Factors: The Case of Silicon Nitride. Physical Review B, 73, Article ID: 195333. http://dx.doi.org/10.1103/PhysRevB.73.195333

[33] Fujita, S., Toyoshima, H. and Sasaki, A. (1988) Bonding Configuration of Fluorine in Fluorinated Silicon Nitride Films. Journal of Applied Physics, 64, 3481. http://dx.doi.org/10.1063/1.341483

[34] Denisse, C.M.M., Troost, K.Z., Habraken, F.H.P.M., van der Weg, W.F. and Hendriks, M. (1986) Annealing of Plasma Silicon Oxynitride Films. Journal of Applied Physics, 60, 2543-2547. http://dx.doi.org/10.1063/1.337118

[35] Nijs, J., Szlufcik, J., Poortmans, J., Sivoththaman, S. and Mertens, R.P. (1999) Advanced Manufacturing Concepts for Crystalline Silicon Solar Cells. IEEE Transactions on Electron Devices, 46, 1948-1969. http://dx.doi.org/10.1109/16.791983

[36] Jeong, J.-W., Rosenblum, M.D., Kalejs, J.P. and Rohatgi, A. (2000) Hydrogenation of Defects in Edge-Defined FilmFed Grown Aluminum-Enhanced Plasma Enhanced Chemical Vapor Deposited Silicon Nitride Multicrystalline Silicon. Journal of Applied Physics, 87, 7551-7557. http://dx.doi.org/10.1063/1.373427

[37] Jiang, F., Stavola, M., Rohatgi, A., Kim, D., Holt, J., Atwater, H. and Kalejs, J. (2003) Hydrogenation of Si from $\mathrm{SiN}_{\mathrm{x}}: \mathrm{H}$ Films: Characterization of H Introduced into the Si. Applied Physics Letters, 83, 931-933. http://dx.doi.org/10.1063/1.1598643

[38] Dekkers, H.F.W., Beaucarne, G., Charifi, H. and Slaoui, A. (2006) Molecular Hydrogen Formation in Hydrogenated Silicon Nitride. Applied Physics Letters, 89, Article ID: 211914. http://dx.doi.org/10.1063/1.2396900 